\title{
Lung transplant—shifting sands!
}

\section{Om Prakash Yadava ${ }^{1} \mathbb{D}$}

Published online: 25 August 2021

(C) Indian Association of Cardiovascular-Thoracic Surgeons 2021
Building on the experimental work of Demikhov and Metras in the 1940s and 50s, the first human lung transplant (LT) was performed by James D. Hardy at University Hospital, Jackson, Mississippi, USA, on 11 June 1963, albeit with a survival of only 18 days. Nevertheless, this opened a new era in the management of end-stage pulmonary disorders. For the succeeding two decades, the forays into LT were few and far between because of high rejection rates and issues related to tracheo-bronchial anastomosis and its stenosis. Anecdotal success stories kept pouring in with Howell Graham as the longest surviving single LT for cystic fibrosis. The introduction of cyclosporine and augmenting the anastomotic vascularisation by limiting the length of the donor bronchus and extrinsic wraps led to the first long-term success of a single LT by Dr. Joel Cooper at the University of Toronto in 1986.

Close on the heels came en bloc double LT, although with continuing tracheal anastomotic issues, leading to the introduction of bilateral sequential LT. The first successful heart-lung transplant (HLT) was performed in 1981 at Stanford University. New technique of Living Donor Lobar Lung Transplantation (LDLLT) evolved in response to the high mortality in those who were too ill to stay on the wait-list for the availability of cadaveric transplantation. Though LDLLT was used initially for only cystic fibrosis, with results matching those of conventional LT, the indications were subsequently broadened to other pathologies too [1]. Currently, LDLLT is practised most in Japan where the wait-list time for a cadaveric LT may be upwards of two years.

Recent years have shown a flurry of activity in the field of LT across the world and more so in India. However, there has been inequitable distribution of LT services in India with North-, Central-, and East-India woefully lagging behind the leaders, viz., South India, followed by western parts of the country, especially the state of Maharashtra. The denominator is touted to be the short supply of donor organs. Maybe

Om Prakash Yadava

op_yadava@yahoo.com

1 National Heart Institute, New Delhi, India this is true for the developed world, but in India, the crux of the matter seems to be reluctance in referring or coming forward of patients for LT. No matter the reasons, this inequitable distribution of the volumes of transplantation need to be addressed. Sure enough, religious bias, cultural factors, and socio-economic parameters play an important role in the reticence to organ donation, but all of these can be suitably manipulated to the advantage of society at large by meaningful interventions by the government and the non-governmental organisations (NGOs). This has been very compulsively demonstrated by the models existing in South India. A caveat here may be in order-usually, political overtones are accorded to mass welfare exercises in India with images, graphics or artwork, blatantly or surreptitiously identifying with the political dispensation in power. This invariably faces headwinds from groups with opposing ideologies and therefore should be scrupulously avoided. If rigorous scientific flavour is maintained, with pure and pristine intent, probably all communities will participate in this noble deed of organ donation and transplantation, which ultimately will work for the benefit of the society itself.

In an evolving programme, organs are usually allotted in chronological order, which is not ideal. The chronological criteria put certain pathologies like pulmonary fibrosis at a disadvantage, because these patients may deteriorate suddenly and catastrophically on the wait-list. 'In a health system based on universality and equity, the application of the criterion of necessity, based on distributive justice, is ideal' [2]. However, the relative merits of the philosophies of 'utilitarianism' and 'distributive justice', based on 'maximum good of the maximum people' versus the need based on the severity of illness respectively, can be debated. New programmes are risk-averse and therefore find refuge in Jeremy Bentham and John Stuart Mill's concept of 'utilitarianism', so that cases relatively early in their progress, and therefore with expectedly better results, are chosen over the more advanced cases, with obviously inferior outcomes. The latter, though may be needing urgent transplantations, lest they risk death on the transplant list, are avoided at the altar of superior results. However, with this need to treat 
'the unequal unequally to promote equity' [2], 'distributive justice' seems right to be gaining in India.

The 'Lung Allocation Score' (LAS) being used in USA has been a major advance in reducing transplant wait-list mortality. It takes into account not only pre-transplant survival, but also the survival post-transplant, to negate the futility of doing the transplant and the wastage of scarce resources. It can be labelled a hybrid model based on the severity of illness, and therefore a marker of 'distributive justice'; as also the long-term survival, which is a hallmark of 'utilitarianism'. LAS has since been adopted in a number of European countries too with salutary results [3]. This also helps reduce the mortality of rapidly progressive diseases like cystic fibrosis and idiopathic pulmonary fibrosis. Since the introduction of LAS, even though more sick and emergent cases are being taken up for LT, yet the results have improved [3, 4]. However, these changes come at a cost, as relatively more stable chronic obstructive pulmonary disease (COPD) patients keep getting relegated on the wait-list. So a balancing act has to be performed of neither performing the LT too early - as that would shorten the overall survival; and in the same breath, not delaying it so long as to increase the wait-list mortality [4]. Needless to say, in this philosophical debate, technical inputs in the nature of the actual pathology, stage of illness, co-morbidities, thoracic cage size compatibility, ABO, other immunological compatibilities, etc. play a dominant role in decision making.

Indications and timing for LT are pathology specific, taking into account the expected survival with and without the transplant. COPD is probably the commonest underlying pathology, followed by restrictive pathologies like idiopathic pulmonary fibrosis, cystic fibrosis, Alpha 1-antitrypsin disease, and primary pulmonary hypertension in that order. Lately, Coronavirus-associated irrecoverable acute respiratory distress syndrome (ARDS) has emerged as a nouveau indication for LT and often controversially jumps the waitlist to the top. This and more shall be the subject matter for the editorial of part 2 of this special issue.

Though both HLT and LT have evolved as extremely effective treatment modalities in the armamentarium of a transplant surgeon to address end-stage pulmonary parenchymal and vascular disease, LT is preferred to HLT essentially due to the improved logistics of the organ availability and its efficient use, as the transplant wait-list mortality still ranges between $14.4 \%$ in adults and $22 \%$ in paediatric population in the developed countries, in a study of 16,973 patients by the United Network for Organ Sharing (UNOS) [5]. Sadly, authentic data is lacking in India, but informal estimates peck it at under $10 \%$. At first glance, that may sound salutary, but on reflection, it puts us in poor light, considering that even though the disease burden is extremely high, yet many deserving patients are not coming forward for LT, either due to ignorance or due to issues related to affordability, availability or accessibility. Despite being in vogue for almost over a quarter of a century, the results of LT can at best be described as sobering with non-cytomegalovirus-associated infections and primary graft dysfunction (PGD) responsible for early mortality. Rejection, PGD, and bronchiolitis-obliterans remain the primary bugbear in long-term outcomes. Of late, LT has gained traction and the results have improved pari passu with advancements in the techniques and technologies, reduction in ischaemia time, less reperfusion injuries, and lesser infections. '5-year survival conditional on survival to 1 year considerably increased from $60 \%$ in [1991-1995] to $67.2 \%$ in [1996-2000], 80.1\% in [2001-2005], 84.7\% in [2006-2010] and $86.4 \%$ [2011-2015]' (Fig. 1) [6]. In the contemporary era, median survival after LT is 6.2 years [4], and conditional on survival to 1-year post-transplant, it is 8.3 [4] to 11.8 years [6]. Moreover, LT improves the quality of life [4]. Newer therapeutics for immune-suppression, modification of chronic lung allograft dysfunction (CLAD), and early diagnosis of rejection and allograft dysfunction will add further to the ever-improving results of LT.

LT is a work in progress and ever-evolving. Indications have been liberalised and both the donor and the recipient criteria have been expanded complementing the technical advances. Donation after circulatory death (DCD) organs, ex vivo lung perfusion (EVLP) systems, and live lobar donors have reduced the wait-list time and mortality. Of the nearly 4600 LTs performed across the world annually, over $90 \%$ were performed in North America and Europe and $80 \%$ of them were bilateral [4]. In India, progress has been made too. However, it has been inequitable with a number of centres doing anecdotal cases. This is worrisome given the fact that volumes are associated with positive outcomes. In contemporary times, major centres from North America and Europe are reporting a 1-year survival rate of $87-93 \%$ and a 5 -year survival rate of 77 to $80 \%$ [6,7]. All-round advances in the criteria optimisation for allocation of donor organs and peri-operative and long-term management strategies have all contributed to these improved results.

Intensive care unit (ICU)-dependant sick patients can be bridged to LT using awake, spontaneously breathing and ambulatory veno-venous extra corporeal membrane oxygenation (ECMO) with results comparable to relatively less sick and non-bridged patients [8,9]. The concept of DCD, either controlled (Maastricht Category III) or uncontrolled DCD (Maastricht Category II), and the use of EVLP systems, especially for uncontrolled DCD, have improved the donation and utilisation of lungs significantly [4]. An interesting category of donor organs come after euthanasia (Maastricht Category V) with the results pouring from countries where euthanasia is legalised like Canada, the Netherlands, and Belgium [4]. The cost of EVLP is prohibitive, and therefore, customised new innovative systems may have 
Fig. 1 'Overall survival after first lung transplantation per transplant era (LTx 1991-2015, $n=860$ ). KaplanMeier curves of overall patient survival after first lung transplantation in UZ Leuven $(1991-2015, n=860)$ stratified per transplant era (a) and conditional on survival to 1 year stratified per era $(\mathbf{b})$. No censoring at retransplantation and exclusion of second Tx $(n=33)$, follow-up until 31 December 2016 (*minimal 1 year for patients transplanted in 2015). Dotted lines represent the 5-year, 10-year, or median survival cut-off. A significant difference in survival (Log rank test) is observed between the various eras during which lung transplantation was performed' (reproduced with permission) [6] (a)

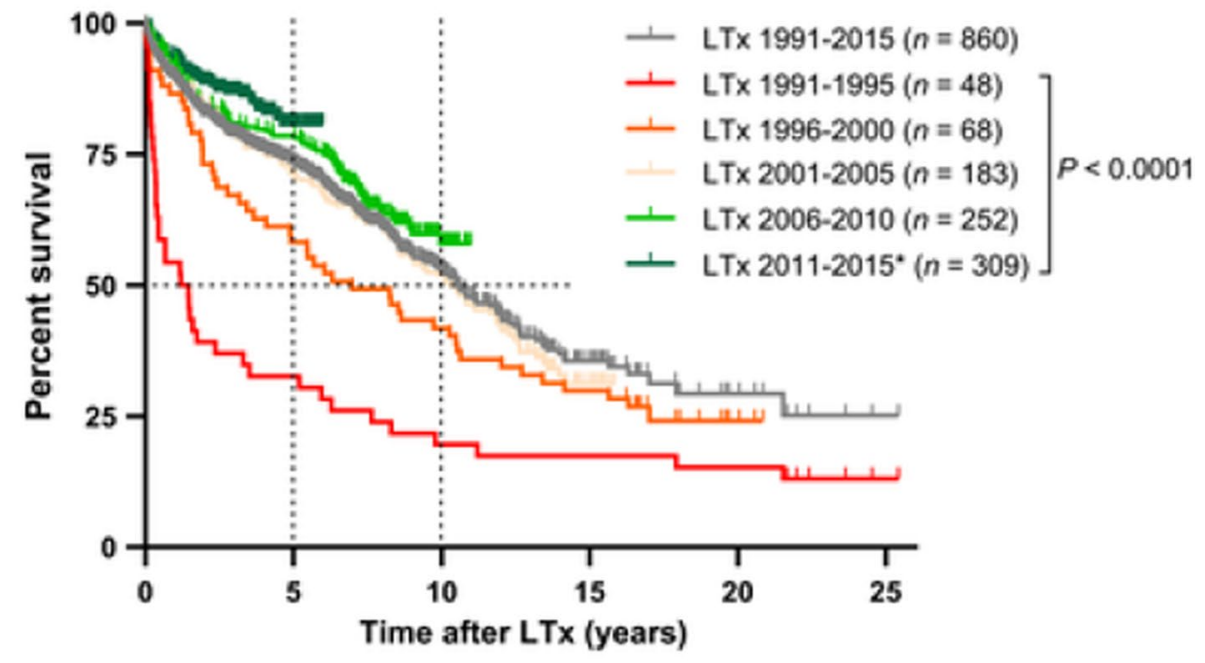

(b) Kaplan-Meier survival conditional on survival to 1 year by transplant era

\section{Survival conditional on survival to 1 year}

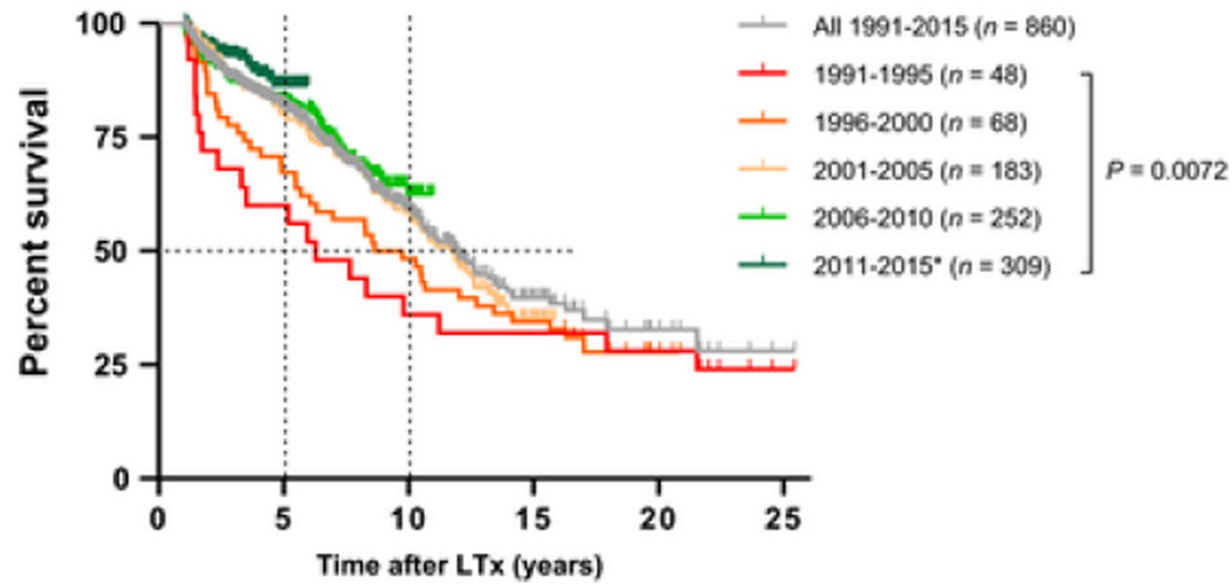

to be developed in our own country. Further efforts can be made in form of advocacy for introducing the opt-out system (presumed consent) as against the opt-in system (informed consent) for organ donation, as has recently been done in the Netherlands and the UK [4].

In Professors Yoshiya Toyoda and Francis Cordova and Drs Sameep Sehgal and Chirantan Mangukia, from Temple University, Philadelphia, USA, we have an array of leading lights in the field as the Guest Editors of this masterly compendium on the art and science of lung transplantation. As a testament to their heft and pelf in the field, we received over 250 pages of scientific material, which would have made a single issue too unwieldy for convenient handling and reading, and therefore, we shall be presenting this thematic issue on lung transplantation in two parts-Part 1 is here for your consumption; Look out for Part 2, soon to follow.
Funding None.

\section{Declarations}

Informed consent Not required.

Conflict of Interest The author declares no competing interests. 


\section{References}

1. Barr ML, Schenkel FA, Bowdish ME, Starnes VA. Living donor lobar lung transplantation: current status and future directions. Transplant Proc. 2005;37:3983-6. https://doi.org/10.1016/j.trans proceed.2005.09.112.

2. Rodrigues-Filho EM, Franke CA, Junges JR. Lung transplantation and organ allocation in Brazil: necessity or utility. Rev Saude Publica. 2019;53:23. https://doi.org/10.11606/S1518-8787.20190 53000445.

3. Gottlieb J, Smits J, Schramm R, et al. Lung transplantation in Germany since the introduction of the Lung Allocation Score. Dtsch Arztebl Int. 2017;114:179-85.

4. van der Mark SC, Hoek RAS, Hellemons ME. Developments in lung transplantation over the past decade. Eur Respir Rev. 2020;29:1-16. https://doi.org/10.1183/16000617.0132-2019.

5. Keeshan BC, Rossano JW, Beck N, et al. Lung transplant waitlist mortality: height as a predictor of poor outcomes. Pediatr Transplant.2015;19:294-300. https://doi.org/10.1111/petr.12390.

6. Raskin J, Vanstapel A, Verbeken EK, et al. Mortality after lung transplantation: a single-centre cohort analysis. Transpl Int. 2020;33:130-41. https://doi.org/10.1111/tri.13540.
7. Benazzo A, Schwarz S, Muckenhuber M, et al. Alemtuzumab induction combined with reduced maintenance immunosuppression is associated with improved outcomes after lung transplantation: A single centre experience. PLoS ONE. 2019;14: e0210443. https://doi.org/10.1371/journal.pone.0210443.

8. Lansink-Hartgring AO, van der Bij W, Verschuuren EA, et al. Extracorporeal life support as a bridge to lung transplantation: a single-center experience with an emphasis on health-related quality of life. Respir Care. 2017;62:588-94. https://doi.org/10.4187/ respcare.05300.

9. Benazzo A, Schwarz S, Frommlet F, et al. Twenty-year experience with extracorporeal life support as bridge to lung transplantation. J Thorac Cardiovasc Surg. 2019;157:2515-2525.e10.

Publisher's note Springer Nature remains neutral with regard to jurisdictional claims in published maps and institutional affiliations. 